\title{
Juventude(s): afinal, que sujeitos sociais são estes?
}

\begin{abstract}
Resumo:
A presente reflexão tem por objetivo discorrer e revisitar três aspectos fundamentais no campo de estudos sobre as juventudes: a problemática conceitual do termo juventude, concebendo-o enquanto construção social e histórica; a concepção plural da(s) juventude(s), efetivamente, marcadas pela diferença/ diversidade bem como a relação das juventudes com o espaço escolar. Tais questões são caras para o campo da Sociologia da Juventude assim como para a sociologia da educação. É recorrente, no campo educacional, o uso da categoria aluno (categoria abstrata e homogênea) para se referir aos jovens sem considerar que se trata de um jovem aluno, ou seja, a dimensão juvenil e as demandas destes sujeitos não entram em cena e/ou estão invisibilizadas. Dito isto, interessa analisar as contribuições teóricas de alguns dos autores expoentes do campo (ABRAMO, 1995; 2005; CARRANO, 2005; DAYRELL, 2001; 2003; 2007; GROPPO, 2017; PAIS, 1990; 2003; PEREGUINO, 2010; 2011; SPOSITO, 2005) para lançar luz sobre tais aspectos. A abordagem teórico-metodológica está ancorada nos estudos da sociologia da educação e da juventude, pesquisa qualitativa e bibliográfica.
\end{abstract}

\section{Palavras-chave:}

Juventude. Juventude(s). Escola.

\section{Youth[s]: after all, what social subjects are these?}

\begin{abstract}
The present reflection aims to discuss and revisit three fundamental aspects in the field of studies on youth: the conceptual problematic of the term youth conceiving it as a social and historical construction; the plural conception of youths effectively marked by difference/diversity and the relationship of youth with the school space. Such questions are important for the area of Youth Sociology as well as for the Sociology of Education. In the educational area the use of the student category (abstract and homogeneous category) is recurrent to refer to young people without considering that it is a young student. That is: the youth dimension and the demands of these subjects do not enter the scene and/or are invisible. It is interesting to analyze the theoretical contributions of some of the leading authors in the field (ABRAMO; CARRANO; DAYRELL; GROPPO; PAIS; PEREGUINO; SPOSITO) to explain such aspects. The theoretical-methodological approach is anchored in the studies of the sociology of education and youth, qualitative and bibliographic research.
\end{abstract}

Keywords: Youth. Youths. School.

1 Doutoranda em Educação pela Universidade Federal do Estado do Rio de Janeiro (UNIRIO). E-mail: julianasouzabarbosa20@gmail.com. ORCID iD: https://orcid.org/0000-0003-4654-4241. 


\section{Juventud: a fin de cuentas, ¿qué sujetos sociales son estos?}

Resumen: La presente reflexión tiene como objetivo discutir y revisar tres aspectos fundamentales en el campo de los estudios sobre la juventud: la problemática conceptual del término juventud, concibiendo como una construcción social e histórica; la concepción plural de juventud (s), efectivamente, marcada por la diferencia / diversidad así como la relación de la juventud con el espacio escolar. Tales preguntas son valiosas para el campo de la sociología juvenil así como para la sociología de la educación. El uso de la categoría estudiante (categoría abstracta y homogénea), en el ámbito educativo, es recurrente para referirse a los jóvenes sin considerar que se trata de un estudiante joven, es decir, la dimensión juvenil y las demandas de estos sujetos no entran en la escena y / o son invisibles. Dicho esto, es interesante analizar los aportes teóricos de algunos de los principales autores en el campo (ABRAMO; CARRANO; DAYRELL; GROPPO; PAIS; PEREGUINO; SPOSITO) para arrojar luz sobre estos aspectos. El enfoque teórico-metodológico está anclado en los estudios de sociología de la educación y la juventud, la investigación cualitativa y bibliográfica.

Palabras clave: Juventud. Joven(s). Escuela.

\section{Introdução}

O campo de estudos sobre juventude assume considerável centralidade na sociedade contemporânea emergindo assim temáticas inerentes a esta parcela da população tais como: o processo de transição para a vida adulta; juventudes e abordagens geracionais; questões acerca da juventude e violências; juventudes periféricas e negras; culturais juvenis; territorialidades juvenis; juventude e o mundo do trabalho; juventude e escola; juventude e privação de liberdade, participação política e juventude dentre outras tematizações que ampliam as lentes para este segmento social. Nesse sentido, debruçar-se sobre a juventude implica compreender as complexidades e singularidades que demarcam tal grupo social, tomando-os sobretudo como sujeitos sociais ativos nas dinâmicas e determinações sociais. Em outras palavras, a juventude não está apática e distanciada dos espaços de decisão, efetivamente, são sujeitos de direitos.

Dito isto, ao entrar neste campo de estudo, uma das questões basilares diz respeito, primeiramente, ao que se compreende por juventude. Em outros termos: O que é a juventude? Que sujeitos sociais são estes? De um ponto de vista analítico, que conceito é este? Desdobrando esta questão inicial, cabe também questionar: Juventude(s) no plural? O que isto significa? Como a escola se insere na vida da juventude? É possível construir diálogos entre juventude e escola? Interessa desdobrar tais questões à luz da perspectiva sociológica e suas contribuições para alargar a compreensão desta juventude. Tais questões são, portanto, os fios condutores para costurar/tecer este texto.

Tais inquietações têm sido objeto de diversos estudos sobretudo no campo da sociologia, psicologia e antropologia, assim, diferentes concepções conceituais surgem destes múltiplos olhares. As reflexões sobre tal conceito apontam seu caráter polissêmico e as diversas perspectivas teóricas que se debruçam sobre estes sujeitos sociais na tentativa de compreender as nuances impressas neste período de vida, mudanças físicas, psicológicas, comportamentais como também de ordem sociocultural, educacional e econômica.

Sucintamente, a juventude pode ser concebida como categoria etária; juventude como reprodução social e simbólica; juventude como um "vir a ser", ou seja, um tempo de preparação para assumir determinadas "funções sociais", decorre daí a noção de juventude como "os sujeitos da falta"; juventude como uma fase "natural" do ciclo da vida, e outras imagens genéricas a respeito. Articulado a isto, estão as representações de rebeldia, crise, risco social (concepção negativa) como também de mudanças, renovação, resistência (concepções positivas). Todas as concepções expostas 
dizem respeito a um dado momento histórico e social, além de variar dependendo das sociedades em questão. Portanto, a categoria juventude é vista e concebida por várias perspectivas. Em síntese, no que tange às concepções e representações da juventude, pode-se inferir que as sociedades a tomam, por vezes, com visões positivas e outras negativas (DAYRELL, 2003; 2007).

A despeito destas interpretações da juventude que emanam de campos de conhecimentos diversos (políticas públicas; antropologia; sociologia; psicologia...), cabe ressaltar que a juventude é, na sociologia, uma categoria social e histórica. A noção sociológica de juventude parte do pressuposto de que a mesma faz parte da estrutura social, é um grupo social que partilha aspectos comuns e distintos. Além disso, a juventude não é universal, ou seja, trata-se de uma categoria sujeita as transformações das sociedades ao longo do tempo/espaço.

Os atuais estudos sobre juventude, ancorados na Sociologia da juventude e na Antropologia, afirmam que para além da concepção "naturalista" de fase transitória de vida, a juventude é uma categoria social (DAYRELL, 2003; GROPPO, 2017; PAIS, 1990; PERALVA, 1997). Groppo (2017, p. 11) afirma que "a juventude é, sobretudo, uma categoria social e não uma característica natural do indivíduo"; Pais (1990, p. 146) aponta que "a juventude é, por conseguinte, produto de um complexo processo de construção social”; Dayrell (2003, p. 41) reitera que o jovem é construído por critérios históricos e culturais, são sujeitos sociais; Peralva (1997, p. 20), salienta também que a juventude é uma condição social e uma representação.

Discorrer sobre juventude pressupõe também compreender a dimensão plural que a constitui, o que implica compreender as nuances presentes nas experiências das diversas juventudes. Em decorrência disto, compreende-se que a noção de condição juvenil traduz este mosaico de possibilidades presentes nas sociedades contemporâneas. Tendo em vista a multiplicidade de atravessamentos e vivências juvenis, Rezende (1989) pontua a necessidade de se abordar a juventude no plural, juventude(s), de modo a abarcar a diversidade sociocultural impressa. Nesta esteira, Groppo (2017), reitera que esta concepção alerta para a existência de grupos sociais concretos, de uma pluralidade de juventudes: de cada recorte sociocultural, classe social, religião, gênero, raça, território etc. Tem-se, efetivamente, uma juventude marcada pela diferença. Dayrell (2007, p. 1114) faz uso de uma expressão bastante significativa para elucidar as múltiplas dimensões da condição juvenil bem como os modos de ser jovem. O autor pontua que a juventude é apenas "uma ponta do iceberg", remetendo assim, à complexidade e amplitude da categoria.

É justamente esta diversidade de juventudes que adentram ao chão da escola. Nesse sentido, é fundamental conhecer os atravessamentos desses jovens bem como suas demandas, se inclinar para a realidade social e escolar desses jovens e compreender seus dilemas, impasses e expectativas, propiciando, assim, possíveis diálogos entre escola e juventude. Esse movimento dinâmico de olhar para esses sujeitos e ampliar suas vozes e narrativas permite que a escola reconfigure suas práticas educativas sobretudo por se tratar de sujeitos que vêm afirmando presenças, trazendo para o campo pedagógico suas vozes dissonantes; inquietações e resistências frente ao sistema desigual e os mecanismos de manutenção da estrutura social no âmbito da instituição escolar.

Em face das considerações iniciais tecidas, o presente artigo tem como objetivo se debruçar sobre os estudos de juventudes, revisitando a literatura do campo para problematizar três aspectos: a própria compreensão da juventude; os modos de ser da juventude, ou seja, os contornos plurais deste grupo social e, por fim, a relação juventude/escola e os possíveis diálogos.

O artigo segue uma abordagem qualitativa, com revisão de literatura do campo da sociologia da juventude e sociologia da educação. Espera-se que as questões desdobradas neste texto possam alargar e contribuir para pesquisadores e interessados nos estudos das juventudes, suscitando a necessidade de se aprofundar cada vez mais as complexidades que envolvem este grupo social. Vale ressaltar que se trata de um texto introdutório e conciso que visa apenas contribuir a partir da retomada crítica dos estudos de autores expoentes/referências do campo. 


\section{Noções e significados múltiplos sobre a(s) juventude(s)}

Mediante tais perspectivas, interessa pontuar a noção de juventude a partir da concepção etária que vigorou e ainda se faz presente enquanto um marcador objetivo na delimitação desta fase de vida. A exemplo disto tem-se a Organização das Nações Unidas (ONU) que considera a juventude àqueles sujeitos inseridos entre 15 e 24 anos, assim como Organização Mundial de Saúde (OMS). Com efeito, a modernidade por meio das categorias etárias propunha estabelecer fronteiras precisas para o curso natural da vida, construindo assim um processo de "cronologização do curso da vida". Neste sentido, a necessidade destes limites etários diz respeito às instituições sociais destinadas a lidar com cada categoria como a família, a escola, a universidade, o asilo, quartel e outras instâncias, desencadeando assim a "institucionalização do curso da vida" (GROPPO, 2017).

Desta forma, cada segmento etário estaria associado a um leque de caracterizações e significações que constituiriam, portanto, os sujeitos inseridos nesta faixa de idade. A exemplo disto, está a juventude como um momento de preparação para assumir certas responsabilidades possibilitando que os mesmos alcancem o status e a posição "privilegiada" da maturidade. Fatores como a entrada no mundo do trabalho; término da escolaridade, saída da casa dos pais, formação da própria família, casamento, filhos, seriam, portanto, marcas da juventude. Tais marcos definiriam a própria noção de juventude.

A problemática referente à esta noção de juventude pelo critério etário reside no fato que tal visão recai em um reducionismo biológico ou biopsicológico uma vez que compreende a juventude como elemento universal e natural inerente à vida humana. Prevalece, nesta perspectiva, os aspectos de ordem biológico e propriedades específicas do desenvolvimento humano conforme veiculado pelos discursos da medicina e da psicologia (GROPPO, 2017).

No entanto, conforme salienta Pais (2003), a noção de juventude não se finda aí, mas implica outras dimensões como a interpretação desta categoria pelo viés sociocultural e histórico, que pode influenciar substancialmente o curso de vida destes sujeitos. Em outras palavras, a juventude não é algo natural e universal conforme preconizado.

Dayrell (2003) explícita que os critérios que constituem a categoria juventude são sociais e históricos, decorre daí a dificuldade de se consolidar uma única definição uma vez que tal concepção varia de sociedade para sociedade como também depende do momento histórico.

Seguindo esta linha de pensamento, Groppo (2017, p. 13) afirma que, do ponto de vista da sociologia, a juventude é uma categoria social visto que a mesma faz parte da própria estrutura social além de fazer parte do imaginário social, como símbolo. $\mathrm{O}$ autor também salienta que a juventude é uma categoria histórica uma vez que existe, concretamente, como representação social e como grupo etário, a juventude não é reconhecida ou formada em todas as sociedades.

Acerca das caracterizações da juventude nos processos de cronologização e institucionalização, Groppo (2017) discorre que tais marcos entraram em declínio desde o final do século passado de modo que os jovens têm construído suas trajetórias fora do enquadrado. A juventude contemporânea opta por permanecer na casa dos pais bem como não contrair o matrimônio e outros aspectos que desconstroem os marcos da condição juvenil elaborada. Desta forma, a juventude contemporânea constitui um mosaico de possibilidades.

De acordo com Groppo (2017, p. 18), pode-se inferir que "houve uma dissociação relativa entre a juventude como categoria etária e a juventude como representação social".

A este respeito, Groppo (2017, p. 15) explicita que:

A noção sociológica da juventude considera que há uma relação complexa entre o fator social e o dado biológico (referente às idades e às transformações orgânicas). Certamente, é difícil e mesmo perigosa a tentativa de determinar de modo puramente biológico a condição juvenil. $\mathrm{O}$ mesmo risco continua quando, ao lado dos aspectos biológicos, considera-se o fator psicológico isolado do mundo social ou se afirmar que atuação social dos jovens tem como determinantes únicos os fatores biopsicológicos, naturais, imanentes à condição juvenil. 
A complexidade referente à juventude enquanto mero marco etário dá-se, sobretudo, pelo caráter relativo deste critério visto que os jovens, suas condutas e comportamentos mudam de acordo com a classe social, o grupo étnico, a nacionalidade, o gênero, o contexto histórico e outras variáveis. O recorte etário não é suficiente para abarcar as diferentes formas de conceber as juventudes. Abramo (1994) reitera que embora a faixa etária seja uma categoria relevante, não se pode perder de vista a juventude como uma construção social e cultural que não se restringe somente aos aspectos de ordens biológico ou jurídico.

Dayrell (2003) também discorre, de maneira crítica, acerca do jovem como sujeito social. O autor concebe a juventude ou o jovem enquanto sujeitos sociais justamente por compreender que:

[...] sujeito é um ser humano aberto a um mundo que possui uma historicidade; é portador de desejos, e é movido por eles, além de estar com outros seres humanos, eles também sujeitos. Ao mesmo tempo é um ser social, com uma determinada origem familiar, que ocupa um determinado lugar social e se encontra inserido em relações sociais. Finalmente, o sujeito interpreta o mundo e dá-lhe sentido, assim como dá sentido à posição que ocupa nele, às suas relações com os outros, à sua própria história e à sua singularidade. (DAYRELL, 2003, p. 43 apud CHALOT 2000, p. 33 e 51).

Dito isto, pode-se inferir que não há uma linearidade ou uniformidade em relação ao conceito de juventude, mas sim uma dinâmica de múltiplos olhares. É efetivamente complexo e árduo definir, com poucas palavras, o que é ser jovem pois tal entendimento pressupõe a compreensão de que a juventude se distingue no tempo e no espaço.

\section{Juventude enquanto construção sócio-histórica}

"A juventude é como um espelho que reflete as diferenças e contradições da sociedade".

Regina Novais (2007)

Ao se perguntar sobre o que é a juventude, comumente tem-se uma noção em mente, mesmo que vaga ou sem algum fundamento científico. É possível inferir que existe, no imaginário social, uma noção do que isto seja.

[...] a palavra juventude evoca sempre múltiplos significados. Ao falar sobre sua juventude, a sociedade expressa seus temores, suas expectativas e suas apostas de futuro. Não por acaso, as imagens sobre a juventude que circulam pela sociedade são ambíguas, ambivalentes e, até mesmo, contraditórias. Idealizações do passado e inseguranças sobre o tempo presente alimentam as projeções otimistas e pessimistas sobre os 'jovens de hoje' (NOVAES, 2007, p. 4).

O fato é que nem sempre existiu juventude, esta categoria ganha visibilidade nas sociedades modernas mediante as significativas mudanças engendradas neste período histórico como o processo de urbanização das sociedades capitalistas, a industrialização e outras transformações no final do século XIX, conforme pontuam Leão e Carmo (2014). Embora pareça banal o questionamento sobre o que é a juventude, de um ponto de vista analítico e social é possível alcançar a riqueza impressa nesta categoria sobretudo no que se refere a forma como as sociedades compreenderam e ainda constroem a juventude.

Philipe Ariès (1981) em sua obra, A história da social da criança e da família, aborda de forma contundente como as fases da vida são construtos históricos e sociais. Ariès (1981) pontua que a ideia da adolescência, conforme se entende hoje, era inexistente nas sociedades pré-industriais. Além disso, 
o autor explicita que a infância não estava dissociada da vida adulta. Neste sentido, o intento de Ariès foi mostrar o lugar assumido pela criança e pela família nas sociedades industriais. Em poucas palavras, a concepção de infância, como de juventude, é tida como categoria sócio-histórica.

No que tange à relação entre as sociedades, suas instituições e a juventude, Leão e Carmo (2014) afirmam que existem muitas concepções e representações acerca desta juventude, as sociedades tomam-nas por vezes com visões positivas e outras negativas. Neste sentido, tem-se a ideia de juventude enquanto fase de transição da vida; juventude associada a um "vir a ser" no sentido de um momento de preparação para ingressar na vida adulta, decorre daí a noção de juventude como "os sujeitos da falta"; juventude como uma fase "natural" do ciclo da vida, e outras imagens genéricas a respeito, questiona-se tais abordagens (NOVAES, 2007). Articulado a isto, estão as representações de rebeldia, crise, risco social (concepção negativa) como também de mudanças, renovação, resistência (concepções positivas). Todas as concepções expostas dizem respeito a um dado momento histórico e social, além de variar dependendo das sociedades em questão.

A respeito destas variações ao longo dos anos, é curioso observar como a juventude contemporânea assume um status que outrora não lhes era atribuído no sentido de que a sociedade concebe a juventude como valor. Assim, Debert (2010) esclarece que a valorização da juventude diz respeito ao desejo, ou de certa maneira, uma exigência de alcançar uma "eterna juventude" de modo que os adultos e velhos apossam-se de formas de consumo e estilos de vida que remetem à um ethos ${ }^{1}$ juvenil. Em contrapartida, no início do século XX, havia um mercado destinado a fazer com que os jovens incorporassem uma conduta austera referente ao universo dos adultos, a ideia seria fazer com que os jovens parecessem adultos, com uma estética do adulto, eram comuns acessórios (charutos, cartolas, bengalas etc.). Neste sentido, Groppo (2017, p. 8) afirma que houve uma inversão na espiral histórica referente "aos anseios da juventude que queria ser vista como velha há um só século atrás no Brasil urbano”.

Segundo Groppo (2017), o caráter de construto social foi efetivamente negado à juventude por meio de estudos que tendiam a acentuar somente a perspectiva biologista e naturalista desta categoria. O autor pontua que, por exemplo, Ortega y Gasset (1987) entendiam a juventude como um curso natural da vida, como algo universal. Assim como também os discursos no âmbito da medicina, ao abordar o crescimento físico do indivíduo e a puberdade, e da psicologia relatando os comportamentos e a fase psicológica da vida, ambas traziam no âmago de suas observações científicas o reducionismo referente às transformações na dimensão físico-mental como inerentes a todos os indivíduos (REZENDE, 1989).

No entanto, na contramão destas concepções, surgem novos movimentos teóricos que trazem como questão central a juventude enquanto categoria social (DAYRELL, 2003; GROPPO, 2017; PAIS, 1990; PERALVA, 1997). Neste sentido, Groppo (2017, p. 11) afirma que "a juventude é, sobretudo, uma categoria social e não uma característica natural do indivíduo"; Pais (1990, p. 146) pontua que "a juventude é, por conseguinte, produto de um complexo processo de construção social”; Dayrell (2003, p. 41) reitera que o jovem é construído por critérios históricos e culturais, são sujeitos sociais; Peralva (1997, p. 20), salienta também que a juventude é uma condição social e uma representação.

Neste sentido, tomando as palavras de Pais (1990, p. 139) acerca desta perceptiva:

A teoria sociológica se vê cada vez mais confrontada com a necessidade de estabelecer rupturas com as representações correntes da juventude, isto é, de estabelecer rupturas com a doxa dominante, tentando, em contrapartida, desenvolver, em relação à realidade socialmente construída que é a juventude, outra doxa mais firme que a espontânea, que sem que hesite, é mesmo uma necessidade, em tornar-se paradoxa.

1 Conjunto dos costumes e hábitos fundamentais, no âmbito do comportamento (instituições, afazeres etc.) e da cultura (valores, ideias ou crenças), característicos de uma determinada coletividade, época ou região. 
Pais (1990), problematiza as rasas concepções de juventudes recorrentes na vida social, sobretudo aquelas que não consideram os atravessamentos e determinantes sociais que fazem com que cada jovem experiencie sua condição juvenil de forma peculiar. Em outras palavras, existem diferenças sociais entre os jovens que são, em certa medida, invisibilizadas em função das aparentes unidades. Em relação a estas dissonâncias juvenis, Pais (1990) denomina de paradoxo no processo de construção sociológica desta categoria.

Em diálogo com a problemática sobre a definição de juventude, Carrano (2005) salienta que:

Os gostos, as atitudes e comportamentos dos jovens se identificam atualmente pela multiplicidade e a ambivalência. É impossível reunir diversas condições sociais de existência em diferentes contextos e caracterizar uma única cultura da juventude. Num mesmo ambiente, em uma mesma festa de família, se pode encontrar o jovem punk e o executivo; o ateu e o evangélico; o sério e o irônico; o que não fala com os pais e aquele que, ao contrário, estabelece com eles uma relação intensa; o que adora o estudo ou a escola e o que considera o esforço intelectual ou a vida escolar um aborrecimento ou perda de tempo. Essas distintas tipologias também não são fixas, caso consideremos os jogos de relações que compõem os processos de formação das muitas identidades de um mesmo indivíduo ou grupo. A juventude é uma categoria sociológica inventada pelos adultos; entretanto, torna-se cada vez mais difícil defini-la. (CARRANO, 2005, p. 157, grifo nosso)

Considerando os caminhos e descaminhos na definição da juventude enquanto categoria social e histórica, interessa refletir como o incipiente campo da sociologia da juventude enquanto subárea da sociologia pode esclarecer, de modo preciso e sucinto, os estudos e pesquisas desenvolvidas ao longo do século XX e XXI.

\section{Sociologia da Juventude: abordagens teóricas}

Uma questão cara que se coloca ao campo da sociologia da juventude diz respeito à compreensão da noção de juventude não apenas enquanto segmento social calcado na categorização por idades (etária) ou por sujeitos sociais portadores de características comuns. Trata-se de adentrar para uma reflexão da juventude concebendo-a como categoria social analítica, em outras palavras a juventude é uma construção histórica e social.

Tendo em vista que são variadas as concepções de juventude, o sociólogo brasileiro Luís Antônio Groppo (2017) através de sua obra intitulada Introdução à sociologia da Juventude propõe sistematizar e categorizar as diversas teorias e olhares para a juventude ao longo do XX e início do XXI. Desta forma, o pesquisador se apossa da produção sociológica europeia e norte-americanas bem como os recentes trabalhos das ciências sociais no Brasil para pontuar como cada momento traz uma dada concepção mais marcante de juventude.

Groppo (2017) cunhou os termos utilizados por Tomaz Tadeu da Silva (2010) ao discorrer sobre a trajetória das teorias do currículo e deslocou para o campo dos estudos de juventude. Sendo assim, denominou de teorias tradicionais, críticas e pós-críticas da juventude.

Neste sentido, tem-se as teorias ditas tradicionais ancoradas na noção de juventude enquanto momento de transição para a idade adulta. Articulada a esta concepção está a ideia de que os jovens usufruem de uma socialização secundária centrada na integração social. Tais abordagens teve grande influência e hegemonia na primeira metade do século XX, tendo como diretriz o estrutural-funcionalismo de Talcott Parsons. Embora tenha recebido contestações de pesquisadores focados nas reflexões acerca dos jovens, ainda assim exerce considerável influência sobretudo nas políticas sociais orientadas por esta concepção tradicional de juventude além de ser recorrente nos discursos da vida social conforme aponta o sociólogo Groppo (2017, p. 23). 
Interessante pontuar que, nesta perspectiva, a juventude ocupa um status inferior, uma vez que, os mesmos são tidos como sujeitos da falta, que necessitam incorporar os padrões sociais já estabelecidos. Neste sentido, cabe ao jovem alcançar e ingressar na maturidade e no status de "adulto" segundo Leão e Carmo (2014). A este respeito, Pais (1990) denomina de "socialização contínua" a incorporação e apropriação dos valores e padrões da geração mais velha pelos jovens. Tais percepções foram bastantes presentes na Europa e Estados Unidos da primeira metade do século XX.

Em suma, a juventude, a partir do estrutural-funcionalismo, é compreendida como uma faixa etária (ou categoria etária) imprimindo um sentido de universalidade, um caráter natural para esta fase de vida. Desta forma, a juventude é uma transição para a vida adulta, intrinsecamente a juventude está associada a um processo de socialização destinada a reproduzir as normas e padrões. Por fim, a juventude tende ao "desvio" ou "anormalidade", ou seja, a não aceitação dos padrões estabelecidos condicionam os jovem à posição de "delinquente juvenil”, Groppo (2017, p. 24).

As teorias críticas referem-se às perspectivas outras acerca dos jovens, novos olhares que acentuam um aspecto positivo para a juventude, compreendendo-as como um potencial na transformação social. Neste sentido, estas teorias problematizam, em certa medida, a concepção "naturalista" da juventude e reflete criticamente sobre a vinculação destes sujeitos à estrutura social.

Estas teorias emergiram na segunda metade do século XX, enfocando a noção de geração, tematizada por Karl Manheim, moratória social e subculturas. Segundo Groppo (2017), as teorias críticas não contestaram, efetivamente, a ideia de socialização secundária vigente na perspectiva tradicional, mas sim pontuou sobre a valorização, o potencial contestador da juventude e sua participação na sociedade. Cabe ressaltar que ocorria em meados da década de 60 movimentos estudantis e contraculturais intempestivas que modificaram o olhar para a juventude apontando uma posição politicamente mais revolucionária.

No seio destas teorias destacam-se as correntes ou variante geracional e classista cada qual, a seu modo, esboçando olhares distintos do que se compreendia por juventudes e sua articulação com a estrutura social. Por um lado, tem-se a tematização das continuidades e descontinuidades intergeracionais e suas implicações na vida social debatido por Manheim ao passo que a corrente classista pontua a relação entre a categoria da juventude com outras variáveis sociais tais como as questões de gênero, étnico-raciais, a condição urbano-rural, a dimensão religiosa e outras faces que ampliam as lentes para a complexa estrutura social e as diversas formas de se viver a juventude.

De acordo com Groppo (2017) as contribuições mais expressivas em relação às teorias críticas foram o reconhecimento do potencial da juventude na sociedade, a compreensão da juventude como tempo e momento de experimentação dos papéis sociais (moratória social), flexibilizando a imposição das normas sociais. Além disso, a ampliação do caráter social e cultural na noção de juventude, desmistificando, em certa medida, a concepção "naturalista". Pontua-se também o reconhecimento de que a juventude experiência a condição juvenil de maneira distinta.

Nesta mesma linha de pensamento, em decorrência dessas nuances no entendimento do que é "ser jovem" e suas demandas, autores como Novais (2006); Abramovay e Castro (2006) discorrem sobre os processos de diferenciações da(s) juventude(s) e a relevância de se apropriar deste conceito no plural abarcando, assim, as especificidades e singularidades no que tange as classes sociais, raça, gênero e sexualidade. Cabe ressaltar que os jovens compartilham de muitos pontos em comum, nesse sentido, as juventudes apresentam uma aparente unidade. No entanto, Pais (2003) afirma acerca da necessidade de se abordar as juventudes do ponto de vista de sua diversidade sociocultural.

Assim, as teorias críticas foram marcantes para os estudos de juventude desconstruindo as concepções tradicionais e trazendo novas inquietações como as questões dos conflitos geracionais, a ampla produção em torno dos movimentos juvenis, a tematização da cultural juvenil, do tempo de lazer dentre outras discussões.

Por fim, as teorias pós-críticas marcam um movimento em que os pressupostos da sociedade moderna mostram-se fragmentados no sentido de configurar um momento de crise dos paradigmas 
sociológicos inerente ao próprio esmigalhamento da modernidade. Neste sentido, a trajetória da sociologia da juventude, a partir da década de 70 até os dias atuais, apresenta certa complexidade.

À exemplo deste momento, Groppo (2017, p. 93) pontua que:

[...] a própria concepção sociológica de juventude implode. Um a um, os elementos tradicionais desta concepção são colocados em causa: a transição para linear da juventude à idade adulta, a socialização como obra das gerações mais velhas que integra o sujeito jovem em uma estrutura social consolidada, a moratória social como postergação do direito ao exercício da sexualidade, do consumo, e da participação social dos jovens, a associação clara entre cada categoria etária e determinadas funções e instituições sociais, entre outros aspectos derivados.

A sociedade moderna torna-se flexível, com certa plasticidade. Nos termos do sociólogo Zygmunt Bauman, a modernidade se liquefaz. O autor se apropria da metáfora do líquido para ilustrar o estado da vida social, denominou-a de modernidade líquida. Neste contexto, as socializações tornam-se mais plurais e ocorrem, de maneira mais ativa, as participações juvenis, são as socializações flexíveis e ativas.

Destacam-se dois movimentos no centro da sociologia da juventude. O primeiro refere-se à ruptura da noção de totalidade, e a possibilidade de abarcar a realidade social como um todo. Isto deve-se, sobretudo, ao aparecimento das concepções pós-modernistas e pós-estruturalistas frente à teoria social e à sociologia da juventude. O segundo movimento diz respeito à ruptura da noção tradicional, ainda presente nas teorias críticas, de socialização, concebendo-a como a um movimento das gerações mais velhas e seus valores incidindo sobre os jovens (GROPPO, 2017).

Ainda nesta leitura das teorias pós-críticas, Groppo (2017, p. 93) analisa o processo de desinstitucionalização do curso de vida e a sociedade capitalista da acumulação flexível; além da metamorfose da juventude em juvenialidade e a sociedade do consumo; o tribalismo e a sociedade pós-moderna, a dita segunda modernidade e a multiplicidade de socializações ativas, como aspectos inerentes a este momento social e histórico das últimas décadas do século XX e início do XXI. Neste labirinto social está a juventude contemporânea.

\section{Da doxa ${ }^{2}$ ao paradoxo ${ }^{3}$ da juventude}

Tendo em vistas que a definição de juventude não pode ser tomada de modo universal, ou seja, não é unívoca visto que ocorre modificações de uma cultura para outra, algumas abordagens apossam-se de critérios que possibilitem construir uma noção de juventude. Desta forma, Pais (2003), aborda tal discussão apresentando dois enfoques cada qual centrado em variáveis distintas. Assim, tem-se a corrente geracional cuja perspectiva apoia-se no critério etário e nas relações intergeracionais e a corrente classista que toma as diferentes classes sociais em que estes jovens se inserem, ou seja, sua origem social.

Neste sentido, interessa compreender como tais abordagens constroem suas concepções de juventude. Trata-se, pois, de compreender que existem diferentes maneiras de ser jovem na contemporaneidade e isto implica reconhecer as condições sociais em que estão inseridos como também considerar que tais distinções conceituais abarcam o âmbito econômico, social e cultural. A sociologia da juventude traça um caminho que permite compreender os diferentes olhares para a noção de juventude, da juventude desviante ao protagonismo juvenil ou, conforme aborda Pais (1990) da aparente unidade de juventude à sua diversidade.

2 Doxa, expressão grega que se refere às opiniões espontâneas e consuetudinárias. Reunião dos pontos de vista que uma determinada sociedade elabora numa dada circunstância histórica, julgando ser uma ação evidente.

3 Prefixo grego para: isto é, oposição à doxa dominante. Contradição ou oposição aparente. 
Segundo Pais (1990, p. 151):

Não há, de facto, um conceito único de juventude que possa abranger os campos semânticos que lhe aparecem associados. Há diferentes juventudes e a diferentes maneiras de olhar essas juventudes corresponderão, pois, necessariamente, diferentes teorias. Poderíamos mesmo agrupar essas teorias em duas principais correntes: a corrente geracional e a corrente classista.

\section{Corrente Geracional}

Conforme citado sucintamente na seção anterior referente às abordagens teóricas da sociologia da juventude, de modo geral a noção de juventude impressa nesta corrente diz respeito a ideia de juventude como uma fase de vida que compreende uma determinada unidade. Está incorporada nesta perspectiva, a transmissão de valores entre as gerações ou, dito de outra forma, a continuidade e descontinuidade dos valores intergeracionais.

Neste sentido, nos termos de Pais (1990), fala-se em uma socialização contínua quando os jovens se apropriam das normas e valores prevalecentes das gerações mais velhas sendo socializados a partir destas, ao passo que as rupturas, conflitos ou crises intergeracionais remete-se aos jovens que confrontam-se aos valores dominantes, em função de algum atravessamento político, ideológico, cultural e social, construindo entre estes jovens uma certa consciência geracional. Cabe ressaltar que as teorias da socialização se ancoram no funcionalismo.

Do ponto de vista dos funcionalistas, os movimentos de rupturas e conflitos entre as gerações são tidos como disfunções, desvios, um problema social. Em contrapartida, as teorias das gerações, predominante também nos anos 50 , apontam que se não houvesse descontinuidades intergeracionais, não existiria a própria teoria das gerações. Nesta perspectiva, as descontinuidades seriam a base da formação da juventude enquanto geração social.

Neste âmbito, vale pontuar também a existência de uma cultura juvenil que, de certa forma, estabeleceria oposição à cultura das gerações adultas. De acordo com Pais (1990) nos anos 60 e 70 predominou uma análise sobre os jovens e sua cultura como algo radical, rebelde e conflituoso, que desejava autonomia frente ao mundo dos adultos, seriam os movimentos culturais juvenis (hippies, beatniks, teddy boys, rastafáris, black music etc).

Ainda em relação às culturas juvenis, a pesquisadora Helena Abramo (1994) ao investigar sobre algumas culturas juvenis na cidade de São Paulo, deparou-se com várias literaturas que ainda compreendem as posturas desviantes e as rupturas de normas e valores desses jovens como algo patológico. Abramo (1994, p. 30) afirma que a noção de desviar como um problema ainda é bastante recorrente. Ainda é predominante a perspectiva tradicional de juventude.

A maior parte dos estudos que se debruçam sobre o problema da delinquência juvenil ressalta o caráter de resultado de um 'defeito' no processo de socialização, provocado por disfunções no sistema social, e é marcada por uma perspectiva corretiva que aponta para a necessidade de 'saneamento' das patologias e para a busca da reintegração desses jovens nos padrões de normalidade.

Resumidamente, a juventude é compreendida como uma categoria homogênea e como categoria etária, daí resultam as várias críticas a esta corrente visto que não considera os universos e dimensões inerentes aos percursos individuais de cada jovem, ou seja, os jovens não vivem situações semelhantes. Toma-se somente a variável idade como importante descartando os demais atravessamentos socioculturais e econômicos.

Pontua-se aqui o caráter relativo da divisão das idades, ou seja, o critério etário, uma vez que nem divisão dos ciclos vitais tampouco as experiências e conhecimentos culturais atribuídos a estas 
fases são universais, ou seja, ocorre uma variação tanto no espaço como no tempo e na estrutura social, segundo Pereira (2005). A esse respeito Feixa (2006) no campo da antropologia da idade, questiona como se dá a interação entre a natureza e a cultura na definição das idades sociais. Sendo assim, este critério parece-me insuficiente para abarcar a amplitude da noção de juventude. Interessa compreender a juventude para além de uma categoria imbuída de reproduzir valores sociais.

\section{Corrente Classista}

Em se tratando da perspectiva classista, como o próprio nome sugere, propõe que a noção de juventude enquanto categoria social está impreterivelmente articulada e atravessada pelos mecanismos de reprodução de classe, ou seja, pelos determinantes sociais que incidem sobre jovens e os posicionamentos de classe dos mesmos. Neste sentido, as culturas juvenis também se enquadram na condição de culturas de classes, portanto, emerge como um produto de relações antagônicas de classe conforme pontua Pais (1990, p. 157).

As culturas juvenis, nesta visão, aparecem como culturas de resistência e apresentam sempre um significado político. Além disso, o corrente classista entende as culturas juvenis como subculturas ou subprodutos da cultura hegemônica, estabelece-se neste caso uma hierarquização em relação à posição dos jovens ocupada na estrutura social.

Pais (1990) pontua que nesta linha de pensamento, a transição dos jovens para a vida adulta é efetivamente marcada por desigualdades sociais. Neste sentido, muitos trabalhos pautados nesta leitura classista de juventude são bastante críticos quando se associa a juventude à uma fase da vida visto que embora compreenda-se a juventude enquanto uma categoria, não se vê a mesma desprovida da sobreposição dominante das relações de classe. Em outras palavras, a corrente classista reduz a noção de juventude às contradições de classe. É justamente por isto que Pais (1990) faz alguns apontamentos críticos referente a esta postura. $\mathrm{O}$ autor problematiza alguns trabalhos de viés classista que tomam os jovens pertencentes à mesma classe sociais de modo homogêneo, como se não houvesse distinções nos modos de vidas destes jovens. Neste sentido, a perspectiva classista recai num determinismo. Em decorrência disto, as distinções simbólicas tais como hábitos de linguagem, vestimentas e outros são comumente observadas como diferenças entre as classes (interclassista) e esporadicamente como diferenças dentro, no interior de uma dada classe (intraclassista).

Assim, Pais (2003, p. 55-56) explicita:

Com efeito, enquanto para a corrente geracional a reprodução se restringe à análise das relações intergeracionais, isto é, à análise da conservação ou sedimentação (ou não) das formas e conteúdo das relações sociais entre gerações; para a corrente classista, a reprodução social é fundamentalmente vista em termos de reprodução de gênero, da raça, enfim de classes sociais.

\section{Cultura Juvenil}

$\mathrm{Na}$ linha de interpretação sociológica de Pais (1990), tanto a corrente geracional quanto a corrente classista concebem a noção de cultura juvenil articulada à cultura dominante. Na perspectiva geracional, a definição de cultura juvenil pauta-se por meio da oposição cultura juvenil versus cultura dominante no sentido de apropriação das culturas das gerações mais velhas, ao passo que na corrente classista a cultura juvenil expressa uma forma de resistência à cultura dominante.

Neste sentido, ocorre uma subordinação das culturas juvenis condicionando-as ao lugar de subculturas. Pelo viés geracional, é bastante recorrente à associação das culturas juvenis enquanto culturas desviantes, decorre daí o olhar para os jovens como sujeitos delinquentes. Já para a corrente 
classista, interessa os processos de incorporação e resistência resultantes da dialética cultura dominante/cultura dominada bem como recorrentes análises de instituições sociais como a escola no sentido da transmissão e reprodução da cultura (hegemônica).

De modo geral, o conceito de cultura em questão refere-se aos diferentes significados e valores de determinados comportamentos juvenis.

Segundo Pais (2003, p. 109):

Em vez de teimosamente me agarrar a uma, e uma só destas correntes teóricas, o exercício a que me proponho é o de olhar as culturas juvenis a partir de diferentes ângulos de observação, de tal forma que umas vezes elas aparecerão como culturas de geração, outras como culturas de classe, outras vezes, ainda, como culturas de sexo, de rua etc.

De acordo com Pais (1990, p. 164), interessa pensar os modos de vida dos jovens e as culturas juvenis para além de uma perspectiva centrada na oposição à cultura dominante, mas sim de compreendê-los através de seus contextos vivenciais, do cotidiano pois é cotidianamente que os jovens constroem suas "formas sociais de compreensão e entendimento que se articulam com as formas específicas de consciência, de pensamento, de percepção e acção". Em poucas palavras, a juventude compartilha, em certa medida, de significados comuns, no entanto, não os vivenciam de forma semelhante.

\section{Juventude com contornos plurais: Juventude(s)}

A necessidade de se abordar a juventude no plural, juventude(s), de modo a abarcar a diversidade sociocultural impressa é um aspecto fundamental nos estudos de juventude(s). Nesta esteira, Groppo (2017), reitera que esta concepção alerta para a existência de grupos sociais concretos, de uma pluralidade de juventudes: de cada recorte sociocultural, classe social, religião, gênero, raça, território etc. Tem-se, efetivamente, uma juventude marcada pela diferença.

Deste modo, as demandas dos jovens moradores de periferias e favelas cujas condições de moradia refletem a completa ausência do poder público mediante as precárias condições sociais distinguem-se dos jovens que não habitam nestes contextos sociais cuja vulnerabilidade social é mais acentuada. $\mathrm{O}$ mesmo ocorre com jovens negros pobres, segmento social cujas trajetórias ainda são marcadas pela exclusão e discriminação racial, em detrimento dos jovens brancos pobres. Em se tratando da questão de gênero, as mulheres negras apresentam também outras demandas distintas de homens negros em função da lógica patriarcal e sexista presente na sociedade. Nesse sentido, as juventudes do ponto de vista sociológico constituem-se enquanto categorias de análise com contornos plurais.

Leão e Carmo (2014) também explicitam que o fato de nascer numa mesma época e contexto não pressupõe que os jovens tenham os mesmos valores e comportamentos. Os autores afirmam que muitos pesquisadores, no campo de estudos das juventudes, têm se apropriado do termo "condição juvenil" na tentativa de compreender a diversidade das juventudes.

Segundo Dayrell (2007, p. 108), do ponto de etimológico, a noção de condição juvenil advém:

Do latim, conditio refere-se à maneira de ser, à situação de alguém perante a vida, perante a sociedade. Mas, também, se refere às circunstâncias necessárias para que se verifique essa maneira ou tal situação. Assim, existe uma dupla dimensão presente quando falamos em condição juvenil. Refere-se ao modo como uma sociedade constitui e atribui significado a esse momento do ciclo da vida, no contexto de uma dimensão histórico-geracional, mas também à sua situação, ou seja, o modo como tal condição é vivida a partir dos diversos recortes referentes às diferenças sociais - classe, gênero, etnia etc. $\mathrm{Na}$ análise, permite-se levar em conta tanto a dimensão simbólica quanto os aspectos fáticos, materiais, históricos e políticos, nos quais a produção social da juventude se desenvolver. 
Dayrell (2007) faz uso de uma expressão bastante significativa para elucidar as múltiplas dimensões da condição juvenil bem como os modos de ser jovem. O autor pontua que a juventude é apenas uma ponta do iceberg, remetendo assim, à complexidade e amplitude da categoria. Dayrell (2007) explicita que a condição juvenil no Brasil apresenta variadas dimensões como a sociabilidade expressa entre os pares, sobretudo, nos espaços e tempos de lazer e as culturas juvenis que abordam as práticas, representações, rituais e símbolos dos jovens.

Nesse sentido, Dayrell (2007) traz inquietações significativas em torno de uma nova condição juvenil no Brasil no sentido de pontuar as tensões e conflitos existentes entre a juventude periférica pobre e a escola. Nesta esteira, o autor pontua que tais situações dissonantes advém das mutações pelas quais passam as sociedades ocidentais de modo que a juventude que se apresenta no chão da escola traz uma nova configuração e condição juvenil distinta das gerações anteriores. É importante salientar, neste sentido, as tensões e ambiguidades vivenciadas pelos jovens que constitui a condição juvenil de cada um deles.

A noção de condição juvenil emerge com bastante significância, pois, conforme pontua Groppo (2017), este conceito crucial relativiza a dimensão biológica e acentua os processos sociais e históricos referente a esta faixa etária. No entanto, embora apresente grande relevância e esteja presente nos discursos midiáticos e políticos, Abramo e Branco (2005) salientam e ponderam acerca da imprecisão conceitual impressa no termo, no sentido de existir vários sentidos implicados na definição da atual condição juvenil. Nesse sentido, Minayo (2011) pontua que se trata de contextualizar as diferenças internas do conceito em questão.

Discorrer sobre juventude pressupõe compreender a dimensão plural que a constitui, o que implica compreender as nuances presentes nas experiências das diversas juventudes. Em decorrência disto, compreende-se que a noção de condição juvenil traduz este mosaico de possibilidades presentes nas sociedades contemporâneas.

\section{Juventudes contemporâneas}

A juventude contemporânea é atravessada por transformações sociais substanciais, próprias deste tempo histórico. Desta forma fatores que afetam a condição juvenil tais como os avanços tecnológicos, mídias digitais, a relação dos jovens com as mudanças no mundo do trabalho, a relação dos jovens com as novas configurações de família denota as novas e múltiplas formas de expressão juvenil. Todas estas mudanças condicionam e proporcionam aos jovens um caminho de desafios e possibilidades de modo a não possibilitar um emolduramento da condição juvenil, visto que esta se modifica de acordo com o momento sócio-histórico (PEREGRINO, 2011).

Inseridos no contexto contemporâneo das incertezas, mobilidades e mudanças, a instabilidade juvenil se faz presente. A esse respeito, Pais (2001) ao referenciar os jovens das últimas décadas do século XX, mais precisamente a década de 90 , se apossa da expressão "geração ioiô" no sentido de pontuar as contradições vivenciadas pelos jovens contemporâneos.

Pais (2001, p. 73) salienta que:

A geração ioiô, pela sua natureza, é uma geração em que o 'tempo flecha' se cruza com o tempo cíclico, tempo de eterno retorno. Os jovens dessa geração tão rapidamente abandonam a escola, adquirem emprego e se casam - deixando de ser jovens e passando a ser adultos - quanto, com a mesma rapidez, caem de novo no desemprego, voltam à condição de estudante e se divorciam, redescobrindo a juventude.

Desta forma, os processos de socializações, as trocas culturais; as formas de resolver e enfrentar as problemáticas e as construções identitárias dos jovens refletem as mudanças na condição juvenil 
contemporânea. Atrelado a isso estão os desafios bem como a necessidade de novas formas de lidar com tais transformações juvenis, tanto do ponto de vista das relações sociais, quanto do ponto de vista das instituições que recebem esses jovens.

O fenômeno das juventudes contemporâneas refere-se aos antagonismos, contradições, limites e possibilidades presente na complexa teia que constitui os jovens desse tempo e espaço histórico. Os jovens deste tempo presente não se posicionam como um "vir a ser", mas sim como sujeitos ativos, jovens como sujeitos de direitos capazes de transformar os contextos sociais e transformarem a si mesmos. Desta forma, vale refletir sobre como estas juventude(s) estabelecem relação com as instituições sociais tal como a escola.

\section{Juventudes e escola: possíveis diálogos?}

As reflexões teórico-conceituais postas anteriormente contribuem para pensar em que medida as juventudes e suas demandas se articulam com o campo educacional escolar. Em outras palavras, tais reflexões descortinam questões, por exemplo: Quem são os jovens que chegam na escola? Tendo em vista que os jovens adolescentes de 15 a 17 anos estão ou deveriam estar alocados na última etapa da educação básica, que corresponde ao ensino médio, cabe questionar também: Quem são os jovens que chegam na escola média? Quais os sentidos do ensino médio para os jovens que o configura?

Ao se debater sobre a relação juventude e escola aparecem pontos de vistas bastante consensuais no que se refere às tensões e conflitos existentes entre ambos. As pesquisadoras Corti, Freitas e Sposito (2001) explicitam a tensão que ocorre no encontro das culturas juvenis com a cultura escolar. As autoras explicam que muitos destes desentendimentos se devem à invisibilidade das demandas juvenis e suas culturas pela escola. "Uma das principais dificuldades da escola em lidar com seus alunos, diz respeito a invisibilidade dos traços propriamente juvenis dessa clientela que são encobertos pela identidade de estudantes" (CORTI; FREITAS; SPOSITO, 2001, p. 36).

Em diálogo com a questão da cultura escolar, o sociólogo francês Pierre Bourdieu no texto A escola conservadora: as desigualdades frente à escola è à cultura bem como no texto Os excluídos do interior, Bourdieu e Chapamgne (1997) explicitam como a escola, enquanto campo de forças e disputas, marginaliza os sujeitos que não detêm determinado arbitrário cultural dominante, embora eles estejam inseridos no interior da escola. Bourdieu e Chapamgne (1997) deflagram os mecanismos internos que sustentam e reproduzem as desigualdades escolares. Tomando, por exemplo, as juventudes periféricas que adentram a escola, é possível observar as tensões acerca da cultura destes jovens em relação aquilo que é preconizado como cultura dominante e/ou superior transmitida pela escola. Não é possível pensar em diálogos entre escola e juventude sem considerar as dimensões socioculturais impressas na trajetória juvenil. A idade, sexo, raça, origem social, moradia e outros aspectos interferem, efetivamente, na trajetória de cada jovem e tais atravessamentos, por vezes, não aparecem na ótica escolar ao se relacionar com este público. Considerar estas dimensões significa apontar a existência de uma sociedade ainda marcada pela desigualdade social que se reflete na precarização das condições de sobrevivência. Trata-se de dar visibilidade à juventude desvelando-a e dando centralidade no que se refere à relação com a escola e suas demandas. A inadequação da escola em relação aos jovens alunos deve-se, em certa medida, ao desconhecimento dos atravessamentos juvenis.

Segundo Dayrell (2007), essa desarmonia entre a juventude e a escola deve-se, também, a mutações das sociedades ocidentais, que consequentemente, incidem nas instituições, ou seja, enquanto a escola afirma que o desempenho insatisfatório na aprendizagem de determinado jovem resulta de sua falta de interesse e comprometimento, as juventudes apontam a falta de diálogo entre o que aprende na escola e suas experiências cotidianas de modo a indagar sobre o propósito 
da instituição e em que medida pode acrescentar em suas trajetórias sociais. O autor propõe uma análise dessa problemática a partir de outro ponto, tomando a escola e a necessidade de novas configurações frente a um novo modo de condição juvenil contemporâneo.

Dayrell (2007, p. 1107) explicita que "o jovem que chega às escolas públicas, na sua diversidade, apresenta características, práticas sociais e um universo simbólico próprio que o diferencia e muito das gerações anteriores", assim é constante os conflitos intergeracionais entre professores mais velhos em contato com a "galera" juvenil e suas perspectivas.

Nesse sentido, evidencia-se a necessidade de a escola considerar as multiplicidades das culturas juvenis que chegam. Nessa esteira, a escola emerge enquanto espaço cultural de encontros e significados outros. Dayrell (2001, p. 136) explicita que:

Analisar a escola como espaço sociocultural significa compreendê-la na ótica da cultura, sob um olhar mais denso, que leva em conta a dimensão do dinamismo, do fazer-se cotidiano, levado a efeito por homens e mulheres, trabalhadores e trabalhadoras, negros e brancos, adultos e adolescentes, enfim, alunos e professores, seres humanos concretos, sujeitos sociais e históricos, presentes na história, atores na história. Falar da escola como espaço sociocultural implica, assim, resgatar o papel dos sujeitos na trama social que a constitui, enquanto instituição.

Pode-se inferir que a falta de motivação para a vida na escola por parte da juventude e a dificuldade de se integrar à cultura escolar tomam novos contornos e significados quando os sentidos da escola centram-se na dimensão dos encontros tecidos naquele espaço. Este é um dos desafios colocados ao se pensar em juventude, escola e possíveis diálogos.

Nesta esteira, Carrano e Martins (2011) reiteram a necessidade da escola se inclinar e reconhecer os processos sociais e culturais contemporâneos produtores das culturas juvenis uma vez que, esses espaços são decisivos na socialização dessa juventude que chega na escola média. Conforme pontuam os autores, trata-se de reconhecer para dialogar, ou seja, a construção do diálogo entre juventude e escola implica, necessariamente, o reconhecimento desses sujeitos e os espaços que os constituem.

Vale ressaltar também que a escola produz certa homogeneização, tende a atender a todos da mesma forma, padronizando os sujeitos em alunos, e, portanto, não toma os jovens enquanto sujeitos socioculturais. Este movimento, simplesmente, apaga a diversidade juvenil do chão da escola. Este apagamento da diversidade juvenil pela concepção homogeneizada de aluno (categoria, por vezes, tida como homogênea e abstrata) impossibilita "compreendê-lo em sua diferença, enquanto indivíduo que possui uma historicidade, com visões de mundo, escalas de valores, sentimentos, emoções, desejos, projetos, com lógicas de comportamentos e hábitos que lhe são próprios". Em suma, a escola não vê, por vezes, a juventude como alunos apenas a categoria alunos por si só, tampouco considera suas demandas e valores juvenis (DAYRELL, 2001, p. 140).

A juventude representa um mosaico de possibilidades. Quando entram em cena a juventude mais o contexto escolar, novos desafios emanam no sentido de pensar possíveis diálogos entre estes sujeitos sociais, suas demandas e nuances com a escola que é o espaço onde estas juventudes tecem projetos de futuros; elaboram a inserção profissional no mercado de trabalho, onde constroem sentidos sobre dimensões fundantes para o curso da vida. Portanto, é possível construir diálogos desde que esta juventude seja reconhecida enquanto sujeitos sociais ativos e de direitos tais como o direito à educação conforme preconiza no Estatuto da Juventude (EJ), de 2013, pela Lei no 12.852. É possível construir diálogos quando as vozes e narrativas destas juventudes são legitimadas pela instituição escolar bem como seus contextos socioculturais. Por fim, possíveis diálogos se efetivam quando há interesse em se inclinar para as contradições, tensões e consonâncias da relação juventude/escola. 


\section{Considerações finais}

As reflexões tecidas ao longo do texto possibilitam entender que o estudo das juventudes é um terreno complexo e fecundo, pois, desvelam as nuances deste grupo social que, paulatinamente, vem ganhando centralidade nas pesquisas e estudos de diversos campos de conhecimentos, sobretudo o campo sociológico.

Fica evidente que a juventude é, dentre a multiplicidade de olhares e seu caráter polissêmico, uma categoria sócio-histórica. Isto significa dizer que a construção da juventude varia de acordo com cada sociedade e momento histórico, a juventude não é universal. As reflexões tecidas também permitem inferir que a noção de juventude não se restringe ao mero critério etário, ou seja, juventude não é uma fase natural do curso da vida, tal perspectiva recai em um reducionismo biológico ou biopsicológico. Com efeito, a juventude é constituída por processos socioculturais e históricos, ela está na estrutura social.

Compreender tal questão é fundamental para alargar as complexidades impressas nos estudos das juventudes. Além disto, esta juventude possui contornos plurais o que implica considerar a existência de modos de ser jovem visto que estes sujeitos sociais são marcados por clivagens no que tange ao sexo, raça, idade, origem social, moradia, gênero e outros recortes. Portanto, trata-se de juventude(s), no plural. Nesse sentido, as juventudes do ponto de vista sociológico constituem-se enquanto categorias de análise com contornos plurais.

Dito isto, as juventudes representam um mosaico de possibilidades. Muitos pesquisadores, no campo de estudos das juventudes, têm se apropriado da noção de "condição juvenil" na tentativa de compreender a diversidade/diferença das juventudes. Desta forma, as juventudes compartilham aspectos comuns e distintos entre si. A noção de condição juvenil emerge de forma significante, pois relativiza a dimensão biológica e acentua os processos sociais e históricos referente a esta faixa etária, além de traduzir as tensões e ambiguidades vivenciadas pelos jovens em seus contextos socioculturais.

É, justamente, esta juventude plural e diversificada que adentra o chão da escola trazendo consigo novas maneiras e sentidos para a instituição escolar. Articular o encontro das culturas juvenis com a cultura escolar é um dos desafios na construção de diálogos possíveis entre juventude e escola. Nesse sentido, é fundamental que a escola reconheça estes sujeitos sociais enquanto protagonistas do fazer educacional, como sujeitos ativos que também possuem conhecimentos construídos nas trocas e sociabilidades juvenis.

Na relação juventude e escola, cabe também pontuar a necessidade de a escola conceber a juventude para além da mera categoria de aluno, tal reducionismo e padronização tende a apagar a diversidade juvenil, ou seja, ocorre a invisibilidade dos traços propriamente juvenis bem como as demandas inerentes deste grupo social no espaço escolar.

Por fim, cabe ressignificar o olhar para a escola tendo-a enquanto um espaço sociocultural. Isto implica conceber a escola a partir da ótica da cultura, considerando o dinamismo, as trocas que se efetivam no cotidiano dos jovens alunos. Nesta perspectiva, quando os sentidos da escola centram-se na dimensão dos encontros tecidos naquele espaço, novos contornos e significados surgem, sobretudo na articulação juventude e escola.

Problematizar tais aspectos significa inclinar-se para a construção de diálogos possíveis, fecundos e qualificados na relação juventude e escola, desvelando assim os antagonismos, contradições, limites, possibilidades e potencialidades presentes na complexa teia que constitui as juventudes desse tempo e espaço histórico. 


\section{Referências}

ABRAMO, Helena Wendel. Condição juvenil no Brasil contemporâneo. In: ABRAMO, Helena Wendel; BRANCO, Pedro Paulo Martoni (org.). Retratos da juventude brasileira. Análise de uma pesquisa nacional.São Paulo: Perseu Abramo, Instituto Cidadania, 2005. 37-72 p.

ABRAMO, Helena; Wendel; BRANCO, Pedro Paulo Martoni (org.). Retratos da Juventude Brasileira: análises de uma pesquisa nacional. Rio de Janeiro: Fundação Perseu Abramo, 2005.

ABRAMOVAY, Miriam; CASTRO, Mary Garcia (coord.). Juventude, Juventudes: o que une e o que separa. Brasília, DF: Unesco, 2006.

ARIÈS, Philipe. História social da infância e da família. Rio de Janeiro: Guanabara, 1981.

BOURDIEU, Pierre. CHAMPAGNE, Patrick. Os excluídos do interior. In: BOURDIEU, Pierre (org.). A miséria do mundo. Rio de Janeiro: Editora Vozes, 1997.

CARRANO, Paulo (org.). Identidades juvenis e escola. In: RAAAB. Construção coletiva: contribuições à educação de jovens e adultos. Brasília, DF: UNESCO, MEC, RAAAB, 2005. 157 p.

CARMO, Helen Cristina. In: CORREA, Licina Maria; ALVES, Maria Zenaide; MAIA, Carla Linhares (org.). Cadernos temáticos: juventude brasileira e Ensino Médio. Belo Horizonte: Editora UFMG, 2014.

CORTI, Ana Paula Oliveira; FREITAS, Maria Virginia de; SPÓSITO, Marília Pontes. O encontro das culturas juvenis com a escola. São Paulo: Ação Educativa, 2001. 36 p.

DAYRELL, Juarez. A escola faz as juventudes? Reflexões em torno da socialização juvenil. Educação \& Sociedade, v. 28, n. 100, p. 1105-1128, 2007.

DAYRELL, Juarez. O jovem como sujeito social. Revista Brasileira de Educação, Rio de Janeiro, n. 24, p. 40-52, set./dez. 2003.

DAYRELL, Juarez. A escola como espaço sociocultural. In: DAYRELL, Juarez (org.). Múltiplos olhares sobre educação e cultura. 2. reimp. Belo Horizonte: Ed. UFMG, 2001.

DAYRELL, Juarez; LEÃO, Geraldo; REIS, Juliana. Juventude, Projetos de Vida e Ensino Médio. Educ. Soc., Campinas, v. 32, n. 117, p. 1067-1084, out./dez. 2011.

DEBERT, Guita Grin. A dissolução da vida adulta e a juventude como valor. Horizontes Antropológicos, Porto Alegre, n. 16, jul./dez. 2010.

FEIXA, Carles. Generación XX: teorías sobre la juventud en la era contemporánea. Revista Latinoamericana de Ciencias Sociales, Niñez y Juventud, v. 4, n. 2, p. 21-45, 2006.

GROPPO, Luís Antonio. Introdução à Sociologia da Juventude. Jundiaí, São Paulo: Editora Paco, 2017. 8-93 p.

LEÃO, Geraldo; CARMO, Helen Cristina. Os jovens e a escola. In: CORREA, Licinia Maria; ALVES Maria Zenaide; MAIA Carla Linhares (org.). Cadernos temáticos: juventude brasileira e Ensino Médio. Belo Horizonte: Editora UFMG, 2014.

MARTINS, Carlos Henrique dos Santos. A escola diante das culturas juvenis: reconhecer para dialogar. Educação, Santa Maria, v. 36, n. 1, p. 43-56, jan./abr. 2011.

MINAYO, Maria Cecília de Souza. A condição juvenil no século XXI. In: MINAYO, Maria Cecília de Souza; ASSIS, Simone Gonçalves; NJAINE, Kathie (org.). Amor e violência: um paradoxo das relações de namoro e do "ficar" entre jovens brasileiros. Rio de Janeiro: Editora FIOCRUZ, 2011.

NOVAES, Regina. Juventude e Sociedade: jogos de espelhos. Sentimentos, percepções e demandas por direitos e políticas públicas. Revista Sociologia Especial: Ciência e Vida, São Paulo, v. 1, n. 2, p. 6-15, out. 2007. 4 p.

NOVAES, Regina. Os jovens de hoje: contextos, diferenças e trajetórias. In: ALMEIDA, Maria Isabel Mendes de; EUGENIO, Fernanda (org.). Culturas jovens: novos mapas do afeto. Rio de Janeiro: Jorge Zahar Editor, 2006.

ORTEGA Y GASSET, José. Juventude. In: ORTEGA Y GASSET, José. Juventude e sociedade. A rebelião das massas. São Paulo: Martins Fontes, 1987.

PAIS, José Machado. Construção sociológica da juventude: alguns contributos. Análise Social, v. XXV, n. 105-106, 1990, p. 139-165

PAIS, José Machado. Culturas juvenis. Lisboa: Imprensa Nacional, 2003.

PERALVA, Angelina Teixeira. O jovem como modelo cultural. Revista Brasileira de Educação, Brasil, n. 5/6, p. 15-24, 1997. 
PEREGRINO, Mônica. Juventude, trabalho e escola: elementos para análise de uma posição social fecunda. Cadernos CEDES, v. 31, 2011, p. 275-291.

PEREGRINO, Mônica. Juventude e escola: elementos para a construção de duas abordagens. In: DAYRELL, Juarez; MOREIRA, Maria Ignez Costa; STENGEL, Márcia. Juventudes contemporâneas: um mosaico de possibilidades. Belo Horizonte: Ed. PUC Minas, 2011.

PEREGRINO, Trajetórias desiguais: um estudo sobre os processos de escolarização pública de jovens pobres. Rio de Janeiro: Garamond, 2010.

PEREIRA, Alexandre Barbosa. De rolê pela cidade: os pixadores em São Paulo. Dissertação (Mestrado em Antropologia) - Universidade de São Paulo, São Paulo, 2005.

REZENDE, Claudia Barcellos. Identidade: o que é ser jovem? Revista Tempo e Presença, São Paulo, n. 240, 1989.

SILVA, Tomaz Tadeu da. Documentos de identidade: uma introdução às teorias do currículo. 3a ed. Belo Horizonte: Autêntica, 2010.

SPOSITO, Marília Pontes. Algumas reflexões e muitas indagações sobre as relações entre juventude e escola no Brasil. In: ABRAMO, Helena Wendel; BRANCO, Pedro Paulo Martoni (org.). Retratos da juventude brasileira: análises de uma pesquisa nacional. São Paulo: Fundação Perseu Abramo; Instituto Cidadania, 2005.

Data de submissão: 31/01/2021

Data de aceite: 19/02/2021 